\title{
Produção de girassol ornamental com uso de águas salobras em sistema hidropônico $\mathrm{NFT}^{1}$
}

\author{
Marlo P. Maciel'2, Tales M. Soares ${ }^{2}$, Hans R. G heyi ${ }^{2}$, \\ Emerson P. L. Rezende ${ }^{2} \&$ G reice X. S. Oliveira ${ }^{2}$
}

\begin{abstract}
RESU M O
Plantas de girassol ornamental 'Sol Vermelho' foram cultivadas em hidroponia com o objetivo de avaliar o uso de águas salobras sobre seu rendimento e qualidade da inflorescência. As águas salobras foram usadas para preparar a solução nutritiva e repor as perdas por evapotranspiração. 0 experimento foi conduzido em delineamento inteiramente aleatorizado com cinco níveis de salinidade da água: 1,51 ; 2,56; 3,86 e 6,19 dS m-1 obtidos pela adição de $\mathrm{NaCl}$ na água doce local $\left(0,47 \mathrm{dS} \mathrm{m}^{-1}\right)$ que também foi usada como testemunha. Cada tratamento foi repetido quatro vezes e cada parcela (com quatro plantas) foi construída para simular um sistema independente da técnica do fluxo laminar de nutrientes (NFT). O bservou-se uma redução linear causada pelo aumento da salinidade da água sobre a altura das plantas, o diâmetro do caule e a massa da matéria seca da parte aérea. Tanto a altura da planta quanto o diâmetro do caule foram reduzidos em $3,2 \%$ e a massa de matéria seca da parte aérea foi reduzida em $5,78 \%\left(\mathrm{dS} \mathrm{m}^{-1}\right)^{-1}$, para cada acréscimo unitário da salinidade da água (dS $\left.\mathrm{m}^{-1}\right)$. Por outro lado, a salinidade da água não afetou o tamanho do capítulo do girassol e não foram registrados sintomas de toxicidade causados pela salinidade. Esses resultados sustentam a viabilidade técnica do uso de águas salobras para produção hidropônica de girassol ornamental.
\end{abstract}

Palavras-chave: Helianthus annuus L., salinidade da água, cultivo sem solo, plantas ornamentais

\section{Production of ornamental sunflower with use of brackish waters in NFT hydroponic system}

\begin{abstract}
Plants of ornamental sunflower 'Sol Vermelho' were grown under hydroponic conditions aiming to evaluate the effects of use of brackish water on its yield and inflorescence (capitulum) quality. The brackish waters were utilized to prepare nutrient solution and to replace water due to evapotranspiration loss. The experiment was carried out in a completely randomized experimental design with five levels of water salinity: $1.51 ; 2.56 ; 3.86$ and $6.19 \mathrm{dS} \mathrm{m}^{-1}$, obtained by addition of $\mathrm{NaCl}$ to local fresh water; this fresh water $\left(0.47 \mathrm{dS} \mathrm{m}^{-1}\right)$ was also studied as control treatment. Each treatment was replicated four times and each experimental unit had four plants in an independent N FT (nutrient film technique) hydroponic system. A linear reduction was observed with increasing water salinity on plant height, stem diameter and fresh and dry matter of plant shoot. Both plant height and stem diameter were decreased by $3.2 \%$, shoot dry matter was decreased $5.78 \%$ with per unit increase of water salinity $\left(\mathrm{dS} \mathrm{m}^{-1}\right)$. $0 \mathrm{n}$ the other hand, water salinity did not affect sunflower capitulum size. Systematic toxicity symptoms caused by salinity were not registered. These findings support the technical feasi bility for hydroponic ornamental sunflower production using brackish waters.
\end{abstract}

Key words: Helianthus annuus L., water salinity, soilless cultivation, ornamental plants

\footnotetext{
${ }^{1}$ Trabalho apresentado durante a II Reunião Sulamericana para Manejo e Sustentabilidade da Irrigação em Regiões Áridas e Semiáridas, Cruz das Almas, BA - 03 a 07 de abril de 2011

${ }^{2}$ CCAAB/U FRB, Campus de Cruz das Almas, Rua Rui Barbosa, 710, Centro, CEP 44380-000, Cruz das Almas, BA. Fone: (75) 3621-2798. E-mail: marlo-maciel@hotmail.com; talesmiler@gmail.com; hans@pq.cnpq.br; emersonpasselle@gmail.com; gximena@gmail.com
} 


\section{INTRODUÇÃO}

A irrigação pode se constituir numa poderosa ferramenta para a agricultura no Semiárido e de fato, hoje, apesar dos desafios, são reconhecidos exemplos de sucesso e potencialidades (Lima et al., 2005; Lacerda \& Oliveira, 2007; Bustamante, 2009), especialmente locados próximos a grandes reservatórios de água de boa qualidade. Por outro lado, são reportados graves problemas de salinização do solo devido à irrigação irracional e/ou o uso de águas salobras (Medeiros \& Gheyi, 2001). Além disso, há grande dificuldade de se levar a irrigação até comunidades difusas nessa Região, para onde a adução de águas superficiais torna-se onerosa.

Dentro desse contexto, tem-se construído propostas de exploração agrícola em condições de baixa disponibilidade quantitativa e qualitativa de água. Assim, algumas pesquisas (Soares et al., 2007; Paulus et al., 2010; Santos et al., 2010; Dias et al., 2010; Alves et al., 2011; Santos Júnior et al., 2011) têm investido no aproveitamento de águas salobras na hidroponia, o que torna-se estratégico, uma vez que, apesar da reconhecida escassez de águas superficiais, tem-se no subsolo do Semiárido uma considerável e inexplorada reserva hídrica, mas que é frequentemente salobra no domínio no embasamento cristalino (Rebouças, 1999).

Empregando águas salobras em hidroponia, espera-se produzir culturas de interesse com maior economia de água e eficiência de insumos, menor risco ambiental e menor depleção do rendimento comercial. Além das hortaliças, principal produto hidropônico do Brasil, culturas de aptidão ornamental são particularmente interessantes, devido à sua alta rentabilidade, para justificar e viabilizar o empreendimento hidropônico com o insumo águas salobras.

Recentemente, a cultura do girassol vem ganhando destaque nas pesquisas com águas de qualidade inferior (Di Caterina et al., 2007; Oliveira et al., 2010; Nobre et al., 2010; Campos et al., 2010; Travassos et al., 2011; Santos Júnior et al., 2011), devido sua relevância para produção de óleo comestível, biodiesel e material ornamental. No ramo da floricultura, segundo Huang (1995), a cultura vem se despontando por ser uma alternativa de oferta de produto de ciclo curto, cores contrastantes e fácil identificação pelo consumidor.

Apesar de não informar limites específicos de salinidade limiar, Ayers \& Westcot (1999) classificam o girassol como planta moderadamente sensível à salinidade. Katerji et al. (1996; 2000), trabalhando em lisímetros com três níveis de salinidade da água $\left(0,9 ; 2,3\right.$ e 3,6 $\left.\mathrm{dS} \mathrm{m}^{-1}\right)$ obtidos com $\mathrm{NaCl} \mathrm{e} \mathrm{CaCl}_{2}$, associados à lâmina de lixiviação de $20 \%$, corroboram com a classificação de Ayers \& Westcot (1999), acrescentando que, quando utilizaram o índice diário de estresse hídrico, o girassol é classificado como tolerante à salinidade. Posteriormente, François (1996) conduziu um experimento com quatro híbridos de girassol, com águas de 1,4 a 8,0 dS m$~^{-1}$, classificando a cultura como moderadamente tolerante à salinidade, com base na salinidade do solo. Recentemente, Chen et al. (2009) reportaram diminuição linear de 4,5 a 5,5\% na produção do girassol para cada acréscimo unitário na salinidade do solo (em dS m${ }^{-1}$ ), mesma magnitude de valor encontrado por François (1996).
Com base no crescimento inicial (duas semanas), Ashraf \& Tufail (1995) avaliaram 45 acessos de girassol, dos quais selecionaram três tolerantes e dois sensíveis à salinidade para um experimento de casa-de-vegetação, delineando que a tolerância da cultura à salinidade não varia no ciclo. Também concluíram que há grande variação na tolerância entre os genótipos, apontando como fatores relevantes as diferenças entre a absorção de cloreto e de potássio, a manutenção da relação K: Na, a seletividade de $\mathrm{Na}$ versus $\mathrm{K}$ e possível ajuste osmótico.

Em relação à resposta de genótipos de interesse ornamental, Grieve \& Poss (2010) avaliaram o aproveitamento de duas qualidades de água de drenagem, com níveis de salinidade 2,5; 5,$0 ; 10,0 ; 15,0$ e 20,0 dS m${ }^{-1}$, sobre a produção de dois genótipos de girassol, reportando que ambos os genótipos têm potencial para o mercado de flores quando produzidas com águas moderadamente salinas. Esses autores observaram a presença de margens foliares necróticas, atribuídas ao cloreto, mas apenas para poucas plantas produzidas com salinidade da água acima de $10 \mathrm{dS} \mathrm{m}^{-1}$. Um resultado expressivo de seu trabalho foi o atendimento, mediante todos os tratamentos, aos padrões de qualidade para tamanho das hastes e das flores. Segundo Rivelli et al. (2010), que trabalharam em hidroponia com 100 $\mathrm{mM}$ de $\mathrm{NaCl}$, com base na partição de massa de matéria seca, as raízes e as folhas do girassol são mais sensíveis à salinidade do que as hastes.

A resposta de uma cultura à salinidade deve ser estudada em função da parte comercializável e, portanto, não seria correto extrapolar limites de qualidade da água para produção de flores de girassol a partir de dados obtidos com a produção de grãos. Também não seria prudente desconsiderar as variações genéticas e as potencialidades de tolerância à salinidade entre cultivares com aptidão ornamental e granífera. Dentro do contexto exposto se propôs o presente trabalho, cujo objetivo foi avaliar a viabilidade técnica de produção de girassol ornamental hidropônico com aproveitamento de águas salobras, averiguando seu rendimento e qualidade comercial.

\section{Material E MÉTODOS}

O trabalho foi desenvolvido no Recôncavo da Bahia, no período de 06/08/2010 a 01/11/10, no campus de Cruz das Almas da Universidade Federal do Recôncavo da Bahia, a 1240' 19" de latitude Sul, 3906'23" de longitude Oeste e altitude média de $220 \mathrm{~m}$.

O experimento foi conduzido em casa-de-vegetação ( 14 x 32 m) do tipo arco e geminada, com $4 \mathrm{~m}$ de pé direito. Foram utilizadas 20 unidades experimentais para o cultivo hidropônico NFT, com base na descrição apresentada por Soares et al. (2009). Cada parcela constituiu-se de: um reservatório plástico com capacidade para $45 \mathrm{~L}$ de solução nutritiva; uma eletrobomba de circulação, autoventilada, com componentes internos em plástico para evitar o efeito corrosivo da solução nutritiva; e um perfil hidropônico feito em polipropileno com aditivo antiUV, com largura de $150 \mathrm{~mm}$ e profundidade de $75 \mathrm{~mm}$, comprimento de $3 \mathrm{~m}$ e com 5 a 6 orifícios espaçados em $0,50 \mathrm{~m}$; em cada parcela foram conduzidas quatro plantas, uma por 
orifício. Também foram montados sistemas de abastecimento automático individualizados para cada unidade experimental.

O controle da irrigação foi feito com auxílio de um temporizador digital. Durante o experimento foi efetivada a seguinte programação diária de irrigação: irrigações a cada 15 min das 06:00 às 11:00 h; irrigação constante das 11:00 às 14:00 $\mathrm{h}$; irrigações a cada $15 \mathrm{~min}$ das 14:00 às 19:00 h; irrigações de 15 min às 21:00, 23:00 e 02:00 h. O experimento foi conduzido em delineamento inteiramente aleatorizado com cinco tratamentos e quatro repetições. Cada parcela foi composta por quatro plantas de girassol. Os tratamentos foram conformados por diferentes níveis de salinidade da água, medidos em termos de condutividade elétrica (CE), quais sejam: 0,$47 ; 1,51 ; 2,56 ; 3,86$ e $6,19 \mathrm{dS} \mathrm{m}^{-1}$. A água doce, com CE de $0,47 \mathrm{dS} \mathrm{m}{ }^{-1}$, foi obtida diretamente da rede de abastecimento local, caracterizando o tratamento controle; os demais níveis de salinidade da água foram obtidos mediante adição de $\mathrm{NaCl}$ à água doce.

Sementes de girassol ornamental variedade 'Sol Vermelho' (ISLA Sementes) foram semeadas em placas cúbicas de espuma fenólica ( $2 \times 2 \times 2 \mathrm{~cm})$, levando-se em média nove dias para germinação. Segundo a empresa produtora, a variedade 'Sol Vermelho' tem ciclo de 70 dias (no verão), flores vermelhas com centro escuro, altura de 2 a 3 m e diâmetro comercial da flor principal de 15 a $18 \mathrm{~cm}$. As mudas foram produzidas em berçário, utilizando a técnica hidropônica NFT. Após 22 dias da semeadura, quando as plantas tinham quatro folhas definitivas e cerca de $10 \mathrm{~cm}$ de altura ocorreu o transplantio para as unidades experimentais. As plantas foram submetidas aos tratamentos tão $\operatorname{logo}$ se deu o transplantio, ou seja, não se adotou qualquer procedimento de alívio contra choque osmótico.

Tanto na produção das mudas quanto na fase experimental propriamente dita foi empregada a solução nutritiva de Hoagland modificada por Epstein \& Bloom (2006) (Tabela 1). Os valores medidos de condutividade elétrica inicial da solução nutritiva, para os níveis crescentes de salinidade da água, foram: 2,10; 2,99; 4,33; 5,46; 7,54 dS m ${ }^{-1}$. Durante o experimento a salinidade e a acidez/alcalinidade da solução nutritiva de cada parcela foram monitoradas.

Tabela 1. Concentração de nutrientes na solução nutritiva usada para o cultivo do girassol

\begin{tabular}{cc}
\hline Nutriente & Concentração $\left(\mathrm{mg} \mathrm{L}^{-1}\right)$ \\
Nitrogênio & 224 \\
Potássio & 235 \\
Cálcio & 160 \\
Fósforo & 62 \\
Enxofre & 32 \\
Magnésio & 24 \\
Boro & 0,27 \\
Manganês & 0,11 \\
Znco & 0,13 \\
Cobre & 0,03 \\
Molibdênio & 0,05 \\
Ferro & 2 \\
\hline
\end{tabular}

Com 28 dias após o transplantio (DAT) houve a reposição de nutrientes, objetivando manter a concentração de nutrientes na solução nutritiva para pronta absorção das plantas. Utilizou- se a diferença entre a CE inicial e a atual do tratamento controle para correção do nível nutricional de todos os tratamentos. Nesse caso, ficou pressuposto que o nível de esgotamento nutricional de todos os tratamentos foi igual; esse procedimento foi necessário, já que o indicador de nível de nutrientes adotado, no caso a CE da solução, não permite distinguir as contribuições das diferentes espécies iônicas.

Durante o experimento algumas plantas foram acometidas por oídio (Erysiphecichoracearum D.C.), sendo o controle bem-sucedido e feito com leite in natura (Jasper et al., 2009) diluído em água a $10 \%$ e aplicado com pulverizador manual.

As plantas foram colhidas de acordo com a abertura do capítulo. Para cada planta colhida foi mensurada a massa de matéria fresca da parte aérea (MFPA), a qual foi fracionada, medindo-se as massas de matéria fresca das folhas (MFF), do caule (MFC) e do capítulo (MFCAP). Posteriormente, o material foi levado à estufa de secagem à $65^{\circ} \mathrm{C}$, obtendo-se as massas de matéria seca da parte aérea (MSPA), das folhas (MSF), do caule (MSC) e do capítulo (MSCAP). Também foi medida a massa da matéria seca do sistema radicular (MSR). O diâmetro externo do capítulo (DECAP), que é formado de uma extremidade das flores estéreis e coloridas até a outra extremidade destas flores, e o diâmetro interno do capítulo (DICAP), que é formado pelas flores viáveis produtoras de sementes, além da altura da planta (AL), da região do colo até o capítulo, foram medidos com régua graduada. O diâmetro do caule (DC) da planta, a $5 \mathrm{~cm}$ acima da região do colo, foi mensurado com uso de paquímetro digital, com dois decimais de precisão. Foram também determinados: o teor de água da parte aérea (TAPA) e a razão raiz/parte aérea (r R/PA) das massas de matéria seca.

Os dados foram tabulados e inicialmente avaliados no software Microsoft Excel. Posteriormente, procedeu-se a análise estatística no software SAS, mediante análises de variância (com o teste F ao nível de 5\% de probabilidade) e de regressão. Os modelos de regressão foram selecionados com base na significância de seus termos e no valor do coeficiente de determinação. Para as funções de primeiro grau, a razão a/b entre os coeficientes angular (a) e linear (b) foi empregada para se estimar as reduções percentuais nas variáveis analisadas por acréscimo unitário da salinidade da água.

\section{RESULTADOS E DISCUSSÃO}

Na Figura 1 está apresentada a variação da condutividade elétrica da solução nutritiva com a reposição de água salobra ao longo do ciclo do girassol. Percebe-se a redução da condutividade elétrica da solução do tratamento que não recebeu água salobra $\left(0,47 \mathrm{dS} \mathrm{m}^{-1}\right)$ devido ao consumo dos nutrientes pela planta, sem correspondente aporte de íons pela água de reposição. Por outro lado, registrou-se o aumento da condutividade elétrica da solução dos tratamentos que receberam água salobra tanto para a produção da solução nutritiva quanto para a reposição da água transpirada pelas plantas; isso se deve ao acúmulo de íons aportados pela água salobra, sem a correspondente absorção desses pelas plantas. Este aumento foi muito mais acentuado para a água salobra 


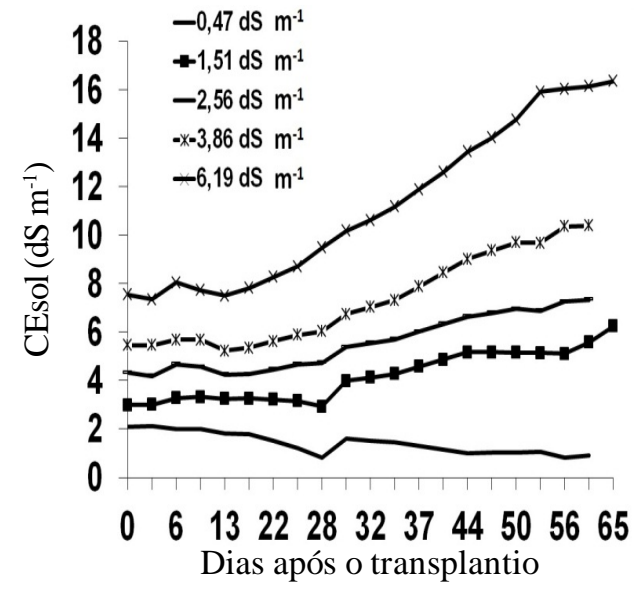

Figura 1. Variação da condutividade elétrica da solução nutritiva (CEsol) ao longo do experimento e em função da salinidade da água

com CE 6,19 dS m ${ }^{-1}$, chegando a uma salinidade média da solução nutritiva de $16,36 \mathrm{dS} \mathrm{m}^{-1}$, no final do experimento.

Soares et al. (2007; 2010) e Alves et al. (2011), trabalhando com alface em hidroponia, também verificaram essa salinização crescente da solução nutritiva devido ao uso de águas salobras na reposição das perdas por evapotranspiração; entretanto, as taxas de salinização registradas no presente trabalho foram maiores devido ao maior consumo hídrico pelo girassol, o que implica em maior aporte de íons.

Ao final do experimento, como as plantas foram colhidas de acordo com a abertura do capítulo, o número de plantas em cada parcela foi variável; por isso, os dados de salinização para as águas com CE 1,51 e 6,19 dS m ${ }^{-1}$ se estendem até os 65 DAT, enquanto para os demais tratamentos se estendem até os 59 DAT.

De maneira geral, o pH oscilou dentro da faixa de 5 e 7 , ou seja, dentro de uma faixa na qual o pH não influencia negativamente as culturas (Figura 2). Apenas ao final do ciclo (a partir de 56 DAT) houve maior oscilação do $\mathrm{pH}$ para as soluções derivadas das águas com CE 2,56 e 6,19 dS m ${ }^{-1}$; isso foi decorrente da impossibilidade técnica de se monitorar o $\mathrm{pH}$ nessa fase, prejudicando as medidas corretivas (acidificação) que vinham sendo adotadas até então. Como a salinidade da

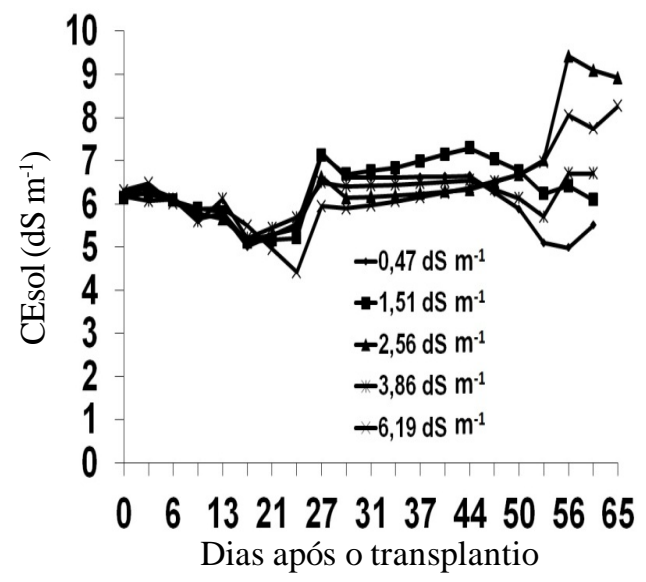

Figura 2. Variação do pH da solução nutritiva ao longo do experimento e em função da salinidade da água água foi causada por $\mathrm{NaCl}$, um sal do qual a hidrólise (de íons capazes de gerar ácido e base fortes) deve ter pouco efeito sobre o pH (Lembo, 2000), a tendência à alcalinidade observada deve ser decorrente do desequilíbrio de cátions e ânions na solução nutritiva devido à própria diferenciação na absorção desses íons pelas plantas (Hinsinger et al., 2003).

Durante o experimento foi observada variação na tonalidade das inflorescências (Figura 3) e em alguns aspectos morfológicos de plantas aleatórias (tonalidades diferentes no caule, do verde ao roxo; presença e ausência de pelos no caule), sem relacionamento com os tratamentos, o que pode se explicar

A.

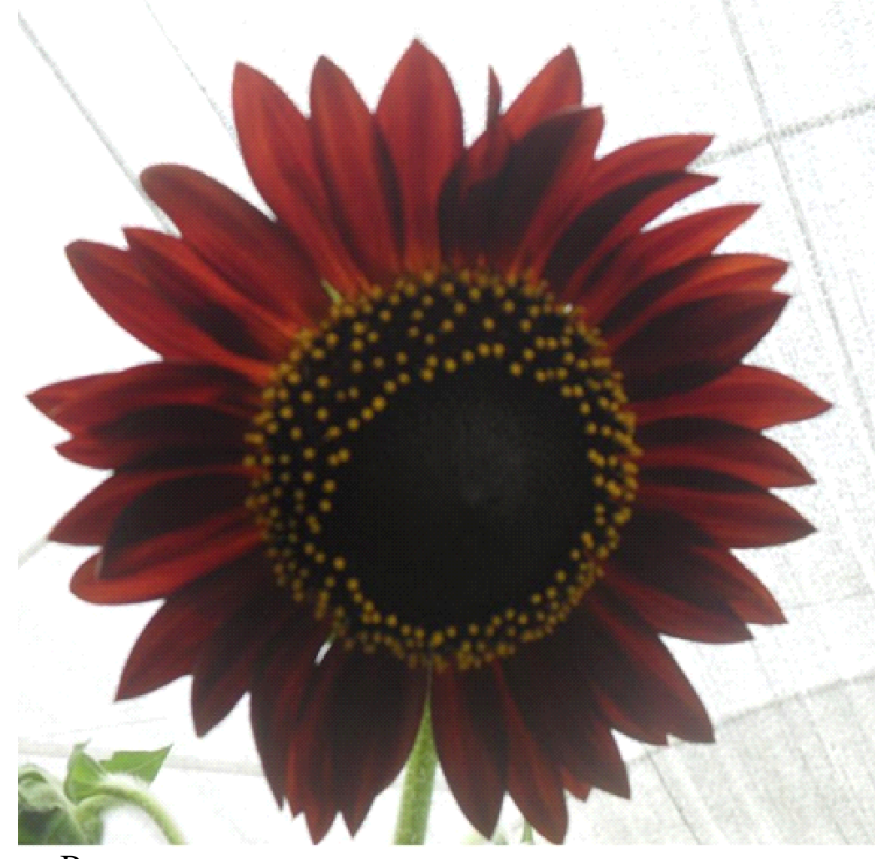

B.

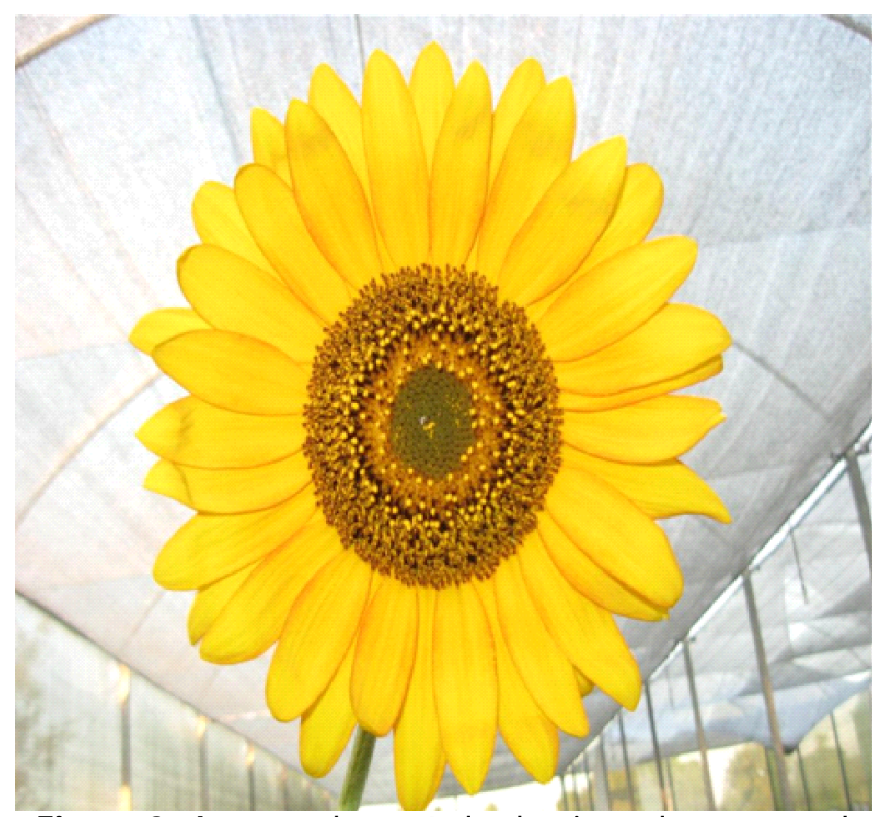

Figura 3. Aspecto do capítulo do girassol ornamental 'Sol Vermelho' após abertura, destacando-se a coloração vermelha na planta acima (A) e a coloração amarela na planta abaixo (B) 
por diferenças genéticas ainda presentes nas sementes da variedade 'Sol Vermelho'. Isso remeteu à preocupação de se ter altos coeficientes de variação (CV) para as variáveis estudadas, talvez ao ponto de comprometer o estudo; entretanto, foram registrados valores de CV inferiores a $24 \%$, como se observa na Tabela 2. Analisando, particularmente, as principais variáveis biométricas para o comércio do girassol ornamental, foram obtidos valores de CV inferiores a 10\%, o que corrobora com os valores apresentados por Amorim et al. (2007), que trabalharam com 15 genótipos brasileiros e argentinos, reportando: $6,82 \%$ para altura da planta até a inserção do capítulo; 8,36\% para diâmetro da haste e 7,67\% para diâmetro do capítulo.

Tabela 2. Coeficientes de variação (CV) e resultado do teste $\mathrm{F}$ referente às variáveis de produção do girassol ornamental 'Sol Vermelho' cultivado com águas sal obras

\begin{tabular}{lrr}
\hline \multicolumn{1}{c}{ Variável } & CV (\%) & Pr > F \\
Massa de Matéria Fresca da Parte Aérea & 11,08 & 0,0011 \\
Massa de Matéria Fresca das Folhas & 13,53 & 0,0165 \\
Massa de Matéria Fresca do Caule & 14,39 & 0,0012 \\
Massa de Matéria Fresca do Capítulo & 20,81 & 0,7606 \\
Massa de Matéria Seca da Parte Aérea & 15,03 & 0,0143 \\
Massa de Matéria Seca das Folhas & 18,58 & 0,1331 \\
Massa de Matéria Seca do Caule & 18,54 & 0,0047 \\
Massa de Matéria Seca do Capítulo & 18,23 & 0,5098 \\
Massa de Matéria Seca das Raízes & 23,44 & 0,7750 \\
Massa de Matéria Seca Total & 14,86 & 0,0403 \\
Teor de Água da Parte Aérea & 1,81 & 0,9883 \\
Razão Raiz/Parte Aérea & 23,44 & 0,0410 \\
Altura da Planta & 9,12 & 0,0279 \\
Diâmetro do Caule & 5,03 & $<0,0001$ \\
Diâmetro Externo do Capítulo & 7,99 & 0,8245 \\
Diâmetro Interno do Capítulo & 9,38 & 0,9656 \\
\hline
\end{tabular}

Para a produção do girassol ornamental variedade 'Sol Vermelho' em sistema hidropônico NFT foram necessários cerca de 67 dias da germinação das sementes até a abertura da inflorescência, quando mais de $50 \%$ das plantas alcançaram o florescimento. A expectativa era obter plantas com cerca de 2 a $3 \mathrm{~m}$ de altura para as plantas-controle (CE da água $0,47 \mathrm{dS} \mathrm{m}^{-1}$ ), conforme indicação da empresa produtora da sementes. No presente trabalho foram registradas para esse tratamento plantas com altura média (na parcela) entre 1,96 a 2,49 m. Na Figura 4 é apresentado o aspecto visual das plantas de girassol aos 48 DAT. A salinidade da água reduziu linearmente a altura das plantas de girassol (Figura 5A). A cada incremento unitário na $\mathrm{CE}$ da água $\left(\mathrm{dS} \mathrm{m}^{-1}\right)$ houve uma redução de cerca de $7 \mathrm{~cm}$; isso correspondeu a uma redução relativa estimada em 3,2\% para cada acréscimo unitário da salinidade da água $\left(\mathrm{dS} \mathrm{m}{ }^{-1}\right)$. Na floricultura comercial, o comprimento comercializável como flor de corte da haste floral do girassol é de cerca de $0,5 \mathrm{~m}$; com esse critério, mesmo para os maiores níveis de salinidade da água estudados não houve depreciação comprometedora para comercialização, corroborando com os dados de Grieve \& Poss (2010), obtidos nos EUA.

O diâmetro do caule também foi reduzido com o aumento da salinidade da água (Figura 5B). Registrou-se uma redução de aproximadamente $0,9 \mathrm{~mm}$ para cada acréscimo unitário na $\mathrm{CE}$ da água (em dS m${ }^{-1}$, o que implica na estimativa de uma redução

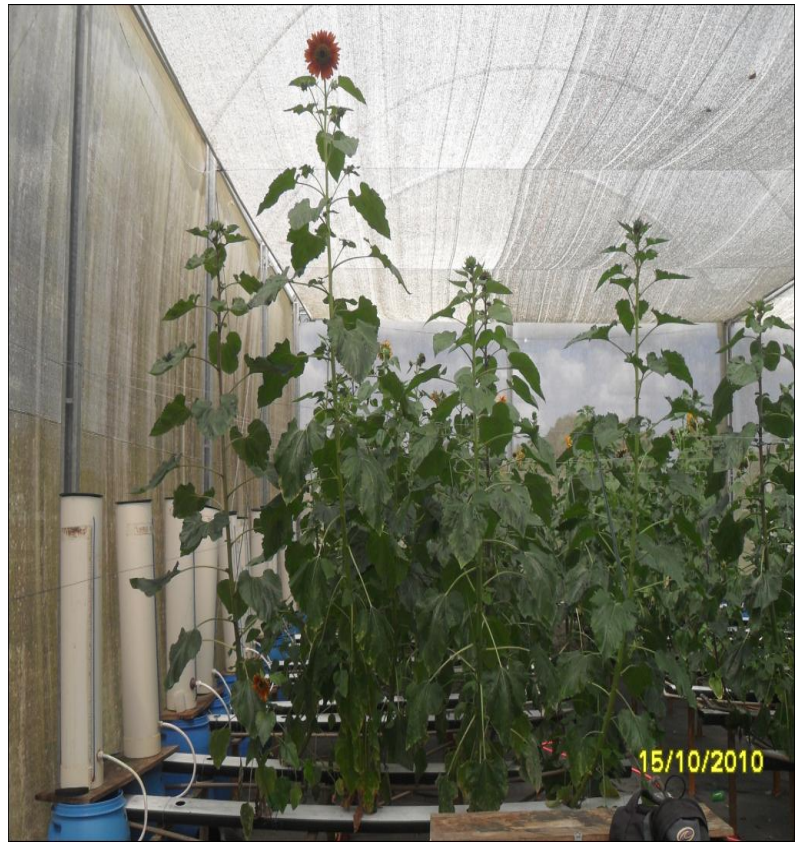

Figura 4. Aspecto geral das plantas de girassol ornamental 'Sol Vermelho' aos 48 DAT

A.

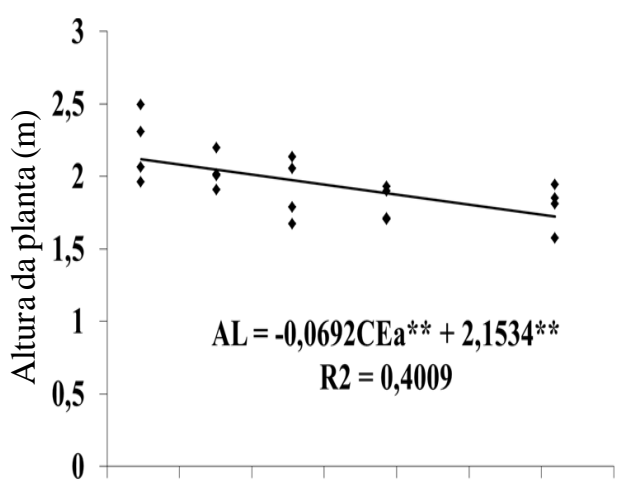

B.

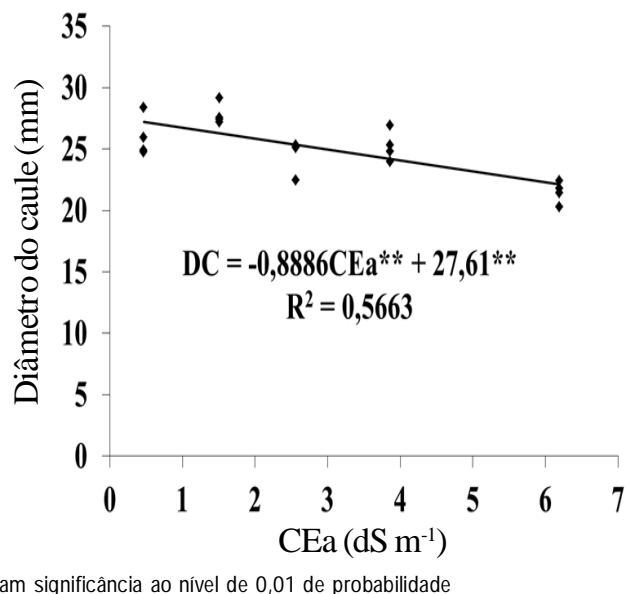

** representam significância ao nível de 0,01 de probabilidade

Figura 5. Relação entre a condutividade elétrica da água (CEa) e a al tura da planta (A) e o diâmetro do caule (B) de girassol ornamental 'Sol Vermelho'

relativa da mesma ordem encontrada para a altura da planta, qual seja: $3,2 \%$ para cada acréscimo unitário da salinidade da água $\left(\mathrm{dS} \mathrm{m}^{-1}\right)$. No Estado de São Paulo, Neves et al. (2005) 
produziram hastes de girassol ornamental 'Sunbright', aos 70 dias após emergência, com diâmetro $13 \mathrm{~mm}$ para hidroponia em vaso e 8,0 mm para solo em vaso, considerando-os satisfatórios. Os valores obtidos no presente experimento, independente do tratamento, são superiores aos limites de 5 a $15 \mathrm{~mm}$, indicados para padrão de qualidade por Grieve \& Poss (2010), que também não reportaram em seu estudo depreciação do padrão de qualidade quando produziram girassol ornamental com águas salobras.

Segundo Curti (2010) é desejável que o diâmetro da haste seja resistente para possibilitar a sustentação da inflorescência do girassol, que geralmente tem maior massa se considerar outras espécies de flor de corte, como a rosa, a gérbera, entre outras.

Os diâmetros externo e interno do capítulo do girassol, variáveis também importantes para a comercialização no ramo da floricultura, não foram influenciados pela salinidade da água, apresentando valores médios de 16,4 e 6,6 cm, respectivamente. Este é um resultado importante, pois mostra que em sistema hidropônico (NFT) e dentro dos níveis de salinidade estudados não houve depreciação da inflorescência do girassol com uso de água salobra. Diferente do estudo de Santos Júnior et al. (2011) que, ao investigarem a variedade de girassol 'EMBRAPA 122/ V-2000' em hidroponia, usando fibra de coco como substrato e irrigando com água salobra, obtiveram para a faixa de CE da solução nutritiva de 1,7 a $11,5 \mathrm{dS} \mathrm{m}^{-1}$, uma redução de $6,6 \%$ no diâmetro interno do capítulo para cada incremento unitário de $\mathrm{CE}$ da água em $\mathrm{dS} \mathrm{m} \mathrm{m}^{-1}$. Os resultados do presente trabalho também divergem dos apresentados por Silva et al. (2009), para a cultivar ornamental 'Dobrada Amarela Anã', submetida à solução nutritiva com $\mathrm{CE}$ de $6,5 \mathrm{dS} \mathrm{m}^{-1} \mathrm{e}$ fração de lixiviação de $50 \%$.

A despeito da aptidão da variedade 'Sol Vermelho' para o mercado de flores ornamentais, não se pode deixar de lado seu potencial de produção de forragem para criação de animais. Passando a analisar os dados referentes ao acúmulo de massa de matéria fresca do girassol ornamental, também foi ajustado o modelo de redução linear para expressar o efeito da salinidade da água (Figuras 6A, B e C).

A massa de matéria fresca da parte aérea foi reduzida em $5,78 \%$ para cada acréscimo unitário da salinidade da água (dS $\mathrm{m}^{-1}$ ), enquanto as massas de matéria fresca do caule e das folhas foram reduzidas em 7,09 e 4,6\% para cada acréscimo unitário da salinidade da água $\left(\mathrm{dS} \mathrm{m} \mathrm{m}^{-1}\right)$, respectivamente. Não houve efeito sobre a massa de matéria fresca do capítulo (Tabela 2), concordando com a ausência de efeito já comentada para os diâmetros externo e interno do capítulo; entretanto, diferentemente das medidas de diâmetro de capítulo, o coeficiente de variação registrado para a massa fresca do capítulo foi de $19,2 \%$. O efeito da salinidade da água sobre a massa de matéria fresca do girassol repercutiu sobre a massa de matéria seca, inclusive com redução relativa da mesma ordem de grandeza (Figura 6D): 5,85\% para cada acréscimo unitário

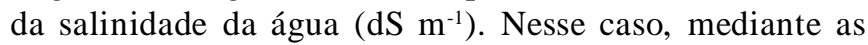
significâncias apresentadas na Tabela 2 , o caule foi o elemento mais sensível à variação da massa de matéria seca da parte aérea do girassol.
A.

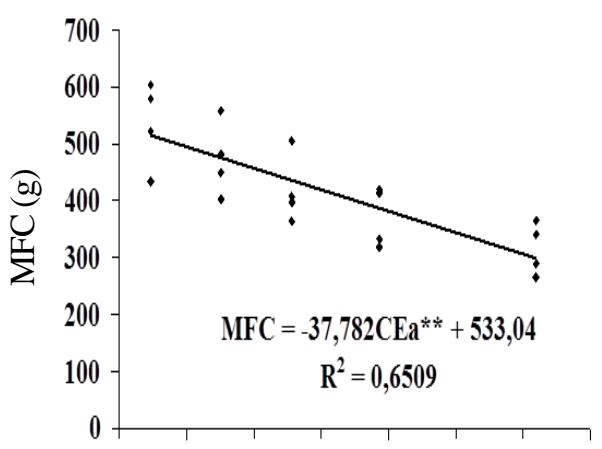

B.

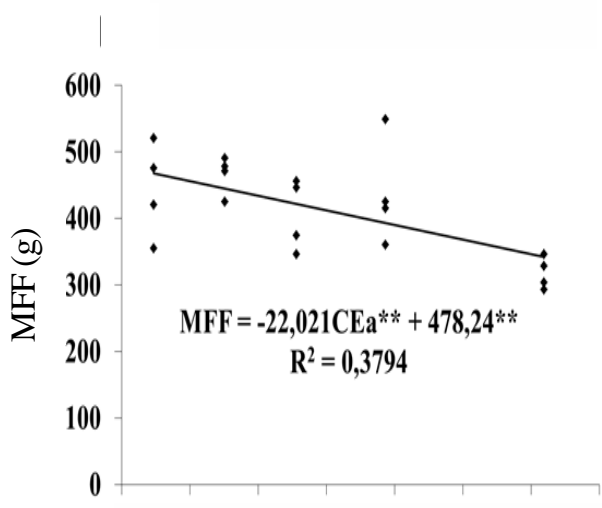

C.

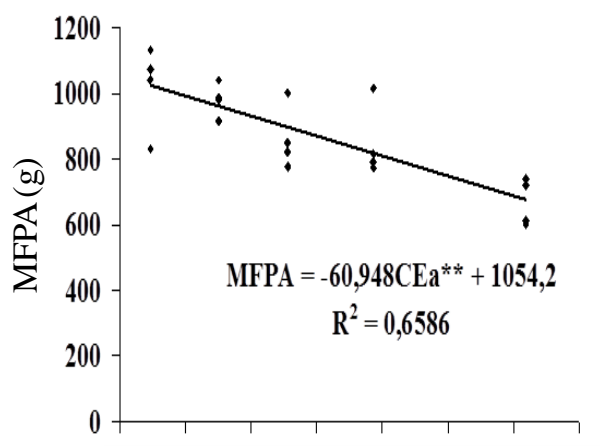

D.

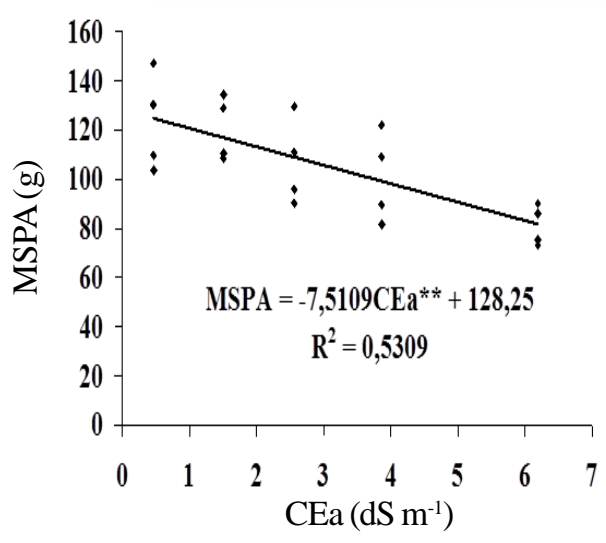

** significância ao nível de $1 \%$ de probabilidade

Figura 6. Massas de matéria fresca do caule (M FC) (A), das folhas (MFF) (B) e da parte aérea (MFPA) (C), e massa de matéria seca da parte aérea (MSPA) (D) do girassol 'Sol Vermelho' em função da salinidade da água (CEa) 
A relação raíz/parte aérea do girassol aumentou linearmente com a salinidade da água (Figura 7), o que foi atribuído à redução da massa de matéria na parte aérea, já que o acúmulo de massa de matéria seca nas raízes não foi prejudicado pela salinidade da água (Tabela 2). No trabalho de Silva et al. (2009), anteriormente citado, as soluções de fertigação de 3,5 e 6,5 dS $\mathrm{m}^{-1}$ reduziram a massa das raízes, em relação à solução de 0,5 $\mathrm{dS} \mathrm{m}{ }^{-1}$. Esse é um contraste interessante porque no presente trabalho se trabalhou com $\mathrm{NaCl}$ e em um sistema de recirculação de solução nutritiva, enquanto Silva et al. (2009) trabalharam com concentrações de nutrientes e em sistema aberto, para o qual se esperaria menor acúmulo de íons na zona radicular.

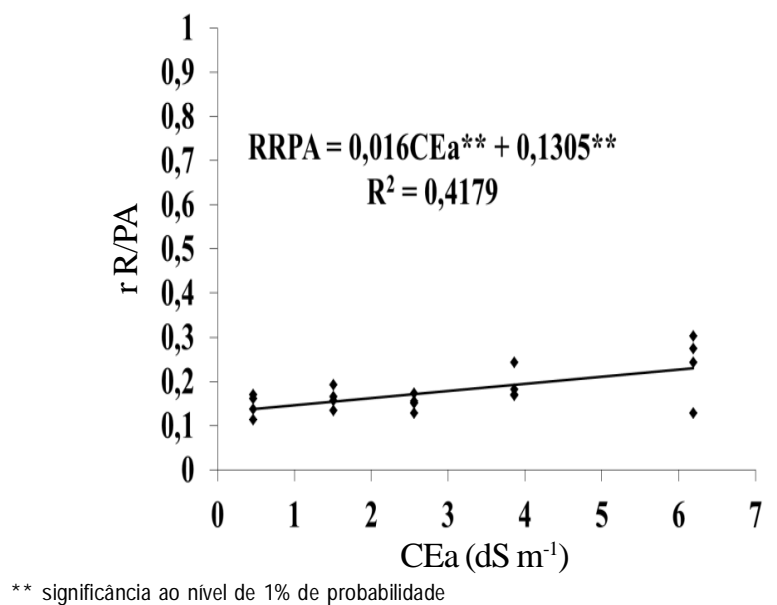

Figura 7. Relação entre as massas de matéria seca da parte aérea e do sistema radicular ( $r$ R/PA) do girassol 'Sol Vermelho' em função da salinidade da água

O principal objetivo do cultivo do girassol ornamental que é a venda de sua haste floral como flor de corte não foi prejudicado pelos níveis de salinidade estudados, pois, mesmo com a redução do porte da planta devido à salinidade, as hastes ainda apresentaram altura e diâmetro suficientes para comercialização, além de tamanho de capítulo inalterado. Segundo Curti (2010), o girassol ornamental pode ser vendido em um feixe com seis hastes pelo preço médio de $\mathrm{R} \$ 15,00$, o que pode variar também conforme a época do ano. Então com um valor médio de $\mathrm{R} \$ 2,50$ por haste, pode-se ter incremento na renda do produtor que possui água salobra natural (ou rejeito de dessalinizador, etc.) e que não tinha perspectiva técnica para seu aproveitamento econômico. Resultados como os do presente trabalho demonstram ser possível a destinação de água de qualidade inferior para fins mais nobres como a floricultura, podendo o restante da planta ser também usado na alimentação animal, sendo, portanto, ferramenta para estudos posteriores de viabilidade econômica.

Vale salientar que no presente estudo não houve o surgimento sistemático de sintomas de toxicidade relacionados à salinidade; apenas em duas plantas de uma das quatro repetições do tratamento com água de $\mathrm{CE} 6,19 \mathrm{dS} \mathrm{m}^{-1}$ foram identificadas folhas com início de necrose; outras três plantas, de tratamentos com baixa salinidade (duas do tratamento com CE da água 1,51 dS m-1 e uma da testemunha) apresentaram rachaduras no caule. Não foram visualizados sintomas no capítulo.

\section{ConClusõES}

A salinidade da água, mesmo proporcionando uma condutividade elétrica da solução nutritiva de até $16,36 \mathrm{dS} \mathrm{m}^{-1}$, não prejudicou o tamanho da inflorescência do girassol ornamental 'Sol Vermelho' nem a qualidade comercial da sua haste, quando cultivado em hidroponia NFT.

\section{AgRAdECIMENTOS}

Os autores agradecem à Fundação de Amparo à Pesquisa do Estado da Bahia (FAPESB) e ao Conselho Nacional de Desenvolvimento Científico e Tecnológico (CNPq), pelo apoio financeiro para execução dos projetos, à Coordenação de Aperfeiçoamento de Pessoal de Nível Superior (CAPES), pela concessão de Bolsa PRODOC (para a autora Greice Ximena Oliveira) e ao Instituto de Ciência e Tecnologia em Salinidade pelas oportunidades de intercâmbio interinstitucional.

\section{LITERATURA CITADA}

Alves, M. S.; Soares, T. M.; Silva, L. T.; Fernandes, J. P.; Oliveira, M. L. A.; Paz, V. P. S. Estratégias de uso de água salobra na produção de alface em hidroponia NFT. Revista Brasileira de Engenharia Agrícola e Ambiental, v.15, p.491498, 2011.

Amorim, E. P.; Ramos, N. P.; Ungaro, M. R. G.; Kiih, T. A. M. Divergência genética em genótipos de girassol. Ciência e Agrotecnologia, v.31, p.1637-1644, 2007.

Ashraf, M.; Tufail, M. Variation in salinity tolerance in sunflower (Helianthus annuus L). Journal of Agronomy and Crop Science, v.174, p.351-362, 1995.

Ayers, R. S.; Westcot, D. W. A qualidade da água na agricultura. 2.ed. Campina Grande: UFPB, 1999. 153p. Estudos FAO. Irrigação e Drenagem, 29 revisado.

Bustamante, P. M. A. C. A fruticultura no Brasil e no Vale do São Francisco: Vantagens e desafios. Revista Econômica do Nordeste, v.40, p.153-171, 2009.

Campos, M. S.; Oliveira, F. A.; Oliveira, F. R. A.; Silva, R. C. P.; Candido, W. S. Efeito da salinidade e fontes de nitrogênio na matéria seca do girassol. Revista Verde de Agroecologia e Desenvolvimento Sustentável, v.5, p165-171, 2010.

Chen, M.; Kang, Y., Wan S.; Liu, S. Drip irrigation with saline water for oleic sunflower (Helianthus annuus L.). Agricultural Water Management, v.96, p.1766-1772, 2009.

Curti, G. L. Caracterização de cultivares de girassol ornamental semeados em diferentes épocas no Oeste Catarinense. Pato Branco: Universidade Tecnológica Federal do Paraná. 2010. 76p. Dissertação Mestrado

Di Caterina, R.; Giuliani, M. M.; Rotunno, T.; De Caro, A.; Flagella, Z. Influence of salt stress on seed yield and oil quality of two sunflower hybrids. Annals of Applied Biology, v.151, p.145-154, 2007. 
Dias, N. da S.; Lira, R. B.; Brito, R. F.; Souza Neto, O. N.; Ferreira Neto, M.; Oliveira, A. M. Produção de melão rendilhado em sistema hidropônico com rejeito da dessalinização de água em solução nutritiva. Revista Brasileira de Engenharia Agrícola e Ambiental, v.14, p.755-761, 2010.

Epstein, E.; Bloom, A. Nutrição mineral de plantas: princípios e perspectivas. 2.ed. Londrina: Editora Planta, 2006. 403p.

François, L. E. Salinity effects on four sunflower hybrids. Agronomy Journal, v.88, p.215-219, 1996.

Grieve, C. M; Poss, J. A. Response of ornamental sunflower cultivars 'Sunbeam' and 'Moonbright' to irrigation with saline wastewaters. Journal of Plant Nutrition, v.33, p.15791592, 2010.

Hinsinger P.; Plassard, C.; Tang, C.; Jaillard, B. Origins of rootmediated $\mathrm{pH}$ changes in the rhizosphere and their responses to environmental constraints: A review. Plant and Soil, v. 248, p.43-59, 2003.

Huang, M.C. New ornamental crops in Asia. Acta Horticulturae, v.397, p.49, 1995.

Jasper, M.; Pria, M. D.; Silva, A. D. Uso do leite de vaca in natura no controle de oídio na cultura da gérbera. Summa Phytopatholica, v.35, n.4, p.322-324, 2009.

Katerji, N.; van Hoorn, J. W.; Hamdy, A.; Karam, F.; Mastrorilli, A. Effect of salinity on water stress, growth, and yield of maize and sunflower. Agricultural Water Management, v30, n.3, p.237-249, 1996.

Katerji, N.; van Hoorn. J. W.; Hamdy, A.; Mastrorilli, M. Salt tolerance classification of crops according to soil salinity and to water stress day index. Agricultural Water Management, v.43, n.1, p.99-109, 2000.

Lacerda, N. B.; Oliveira, T. S. Agricultura irrigada e a qualidade de vida dos agricultores em perímetros do Estado do Ceará, Brasil. Revista Ciência Agronômica, v.38, n.2, p.216-223, 2007.

Lembo, A. Química: realidade e contexto: físico-química. São Paulo: Ática, 2000. v.2.496p.

Lima, M. L. S.; Faria, R. A.; Passos, A. T. N.; Silva, L. S. Diagnóstico da economia agrícola do pólo irrigado AçuMossoró. Revista Caatinga, v.18, n.3, p.136-142. 2005.

Medeiros, J.F.; Gheyi, H.R. Riscos de salinidade em áreas irrigadas. In: Miranda, J. H.; Pires, R. C. M. (ed.). Irrigação. Piracicaba: FUNEP, 2001. cap.5, p. 255-314. Série Engenharia Agrícola, Irrigação, 1

Neves, M. B.; Buzetti, S.; Castilho, R. M. M.; Boaro, C. S. F. Desenvolvimento de plantas de girassol ornamental (Helianthus annuus L.) em vasos, em dois substratos com solução nutritiva e em solo. Científica, v.33, n.2, p.127-133, 2005.
Nobre, R. G.; Gheyi, H. R.; Correia, K. G.; Soares, F. A. L.; Andrade, L. O. Crescimento e floração do girassol sob estresse salino e adubação nitrogenada. Revista Ciência Agronômica, v. 41, p.358-365, 2010.

Oliveira, F. A.; Oliveira, F. R. A.; Campos, M. S.; Oliveira, M. K. T.; Medeiros, J. F.; Silva, O. M. P. Interação entre salinidade e fontes de nitrogênio no desenvolvimento inicial da cultura do girassol. Revista Brasileira de Ciências Agrárias, v.5, p.479-484, 2010.

Paulus, D.; Dourado Neto, D.; Frizzone, J. A.; Soares, T. M. Produção e indicadores fisiológicos de alface sob hidroponia com água salina. Horticultura Brasileira, v.28, p.29-35, 2010.

Rebouças, A. C. Águas subterrâneas. In: Rebouças, A. C.; Braga, B.; Tundisi, J. G. (ed.). Águas doces no Brasil: capital ecológico, uso e conservação. São Paulo: Escrituras, 1999. cap. 4, p. 117-151.

Rivelli, A. R.; Maria, S. de; Pizza, S. Gherbin, P. Growth and physiological response of hydroponically-grown sunflower as affected by salinity and magnesium levels. Journal of Plant Nutrition, v.33, p.1307-1323, 2010.

Santos, A. N.; Soares, T. M.; Silva, E. F. F.; Silva, D. J. R.; Montenegro, A. A. A. Cultivo hidropônico de alface com água salobra subterrânea e rejeito da dessalinização em Ibimirim, PE. Revista Brasileira de Engenharia Agrícola e Ambiental, v.14, p.961-969, 2010.

Santos Júnior, J. A.; Gheyi, H. R.; Guedes Filho, D. H.; Dias, N. da S.; Soares, F. A. L. Cultivo de girassol em sistema hidropônico sob diferentes níveis de salinidade. Revista Ciência Agronômica, v.42, p.842-849, 2011.

Silva, T. G. F.; Zolnier, S.; Grossi, J. A. S.; Barbosa, J. G.; Moura, C. R. W.; Muniz, M. A. Crescimento do girassol ornamental cultivado em ambiente protegido sob diferentes níveis de condutividade elétrica de fertirrigação. Revista Ceres, v. 56, p.602-610, 2009.

Soares, T. M.; Duarte, S. N.; Silva, E. F. F.; Jorge, C. Combinação de águas doce e salobra para produção de alface hidropônica. Revista Brasileira de Engenharia Agrícola e Ambiental, v.14, p.705-714, 2010.

Soares, T. M.; Duarte, S. N.; Silva, E. F. F.; Melo, R. F.; Jorge, C.A.; Oliveira, A. S. Experimental structure for evaluation of saline water use in lettuce hydroponic production. Irriga, v.14, p.102-114. 2009.

Soares, T. M.; Silva, E. F. F.; Duarte, S. N.; Melo, R. F.; Jorge, C. A.; Bonfim-Silva, E. M. Produção de alface utilizando águas salobras em sistema hidropônico. Irriga, v.12, p.235-248, 2007.

Travassos, K. D.; Soares, F. A. L.; Gheyi, H. R.; Silva, D. R. S.; Nascimento, A. K. S.; Dias, N. da S. Produção de aquênio do girassol irrigado com água salobra. Revista Brasileira de Engenharia Agrícola e Ambiental, v.15, p.371-376, 2011. 